\title{
Influence of Film Thickness on Structural and Optical Properties of Sol - Gel Spin Coated $\mathrm{TiO}_{2}$ Thin Film
}

\author{
P. Malliga ${ }^{1}$, J. Pandiarajan ${ }^{2}$, N. Prithivikumaran ${ }^{2} \&$ K. Neyvasagam ${ }^{3}$ \\ ${ }^{1}$ Department of Physics, V.V.Vanniaperumal College for Women, Virudhunagar - 626001, Tamilnadu, India. \\ ${ }^{2}$ Nanoscience Lab, Department of Physics, VHNSN College, Virudhunagar-626001, Tamilnadu, India. \\ ${ }^{3}$ Department of Physics, The Madura College, Madurai-625011, Tamilnadu, India.
}

\begin{abstract}
Titanium dioxide thin films have been prepared from the solution of TTIP (Titanium Tetra Isopropoxide), Acetic acid and Ethanol on the glass substrates by sol-gel spin coating technique. In the present work, the $\mathrm{TiO}_{2}$ thin films have been analyzed for different coating cycles which were annealed at $450^{\circ} \mathrm{C}$ for one hour. The annealed films were characterized by X - Ray diffraction (XRD) method, UV - Visible \& Photoluminescence (PL) spectroscopy, Field Effect Scanning Electron Microscopy (FESEM) and Energy Dispersive X - Ray Analysis (EDAX).The XRD results show that the crystallite size increases from $6.3 \mathrm{~nm}$ to $35.5 \mathrm{~nm}$ with increase in number of coating cycles. The transmittance of the film and the optical band gap are found to decrease with increase in number of coating cycles. The room temperature PL spectra of $\mathrm{TiO}_{2}$ thin films show blue and green emissions at $485 \mathrm{~nm}$ and $530 \mathrm{~nm}$ with excitation at $410 \mathrm{~nm}$. The surface morphology shows rough surface with irregular particles. The stoichiometric ratio of the film was confirmed by EDAX analysis. The results of structural and optical characteristic study suggest that the sol-gel spin coated nanocrystalline $\mathrm{TiO}_{2}$ thin films can have high potential application in photo catalytic activities.
\end{abstract}

Keywords: Film thickness, FESEM, PL, Spin coating method, $\mathrm{TiO}_{2}$ thin film.

\section{Introduction}

Transparent conducting oxide (TCO) materials are of great interest due to their distinctive physical, chemical, optical and optoelectronic properties. Among the various TCO materials, $\mathrm{TiO}_{2}$ plays a most promising role in several areas of research because of its high efficient photo catalytic activity, high refractive index, resistance to photo corrosion, chemical stability, low cost and non-toxicity [1,2]. For more than a decade, studies have mainly concentrated on the effect of $\mathrm{TiO}_{2}$ particle size on its photo catalytic activity. Decrease in the size of the particle causes an increase in the photo catalytic activity of the $\mathrm{TiO}_{2}$ films [3,4]. Among the three principal crystalline forms (anatase, rutile and brookite) of Titania, rutile is not a good photo catalyst but optimal photo catalytic efficiency is obtained with a mixture of anatase and a smaller percentage of rutile [5]. Over the past several years, a large number of applications of photo catalytic activity have been examined and reported in the literature. They include self-cleaning $\mathrm{TiO}_{2}$ coated glass covers for highway tunnel lamps[6] and a flow type photo reactor for water purification[7].

Nanocrystalline $\mathrm{TiO}_{2}$ films have been prepared using various methods such as physical vapour deposition[8], plasma enhanced chemical vapour deposition (PECVD)[9], metal organic decomposition (MOD)[10] and Sol-Gel process[11,12]. Among these, sol-gel technique has many advantages over other synthesis techniques; such as excellent control over chemistry, homogeneity, purity and crystalline phase [13].

In this work we report on the preparation of nanocrystalline $\mathrm{TiO}_{2}$ thin films by Sol-Gel method using spin coating technique and the effect of number of coating cycles on structural \&optical properties and surface morphology with elemental analysis.

\section{Materials And Methods}

Thin films of $\mathrm{TiO}_{2}$ were deposited from a solution of analytical grade Titanium tetra isopropoxide ( $\mathrm{Ti}$ $\left.\left(\mathrm{OC}_{3} \mathrm{H}_{7}\right)_{4}\right)$, ethanol and acetic acid using Spin coating machine. Commercial transparent glass slides $(2.5 \mathrm{~cm} \mathrm{x}$ $2.5 \mathrm{~cm}, 1.35 \mathrm{~mm}$ thickness) used as substrates were kept in hot chromic acid at $60^{\circ} \mathrm{C}$ for one hour; cleaned Ultrasonically (using ultrasonicator) with distilled water for 30 minutes and finally cleaned with acetone before use. The process of preparation of $\mathrm{TiO}_{2}$ thin films is shown in Fig. 1. 


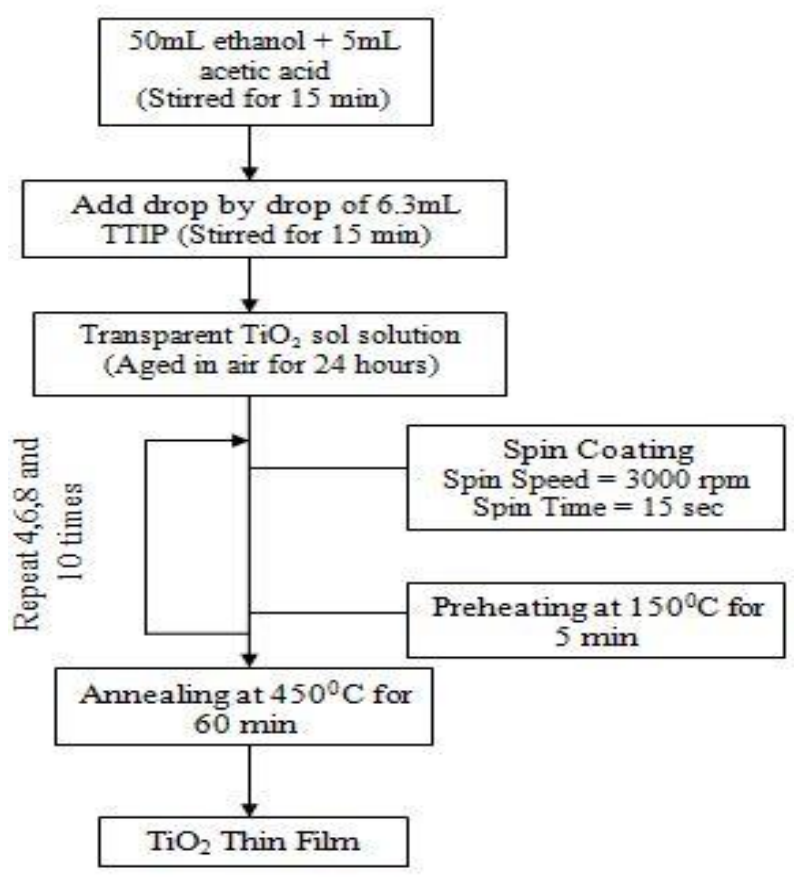

Fig. 1 - Flowchart for the preparation of $\mathrm{TiO}_{2}$ thin films

The spin coated nanocrystalline $\mathrm{TiO}_{2}$ thin films were subjected to XRD, UV-Visible, Photoluminescence and SEM-EDAX analyses. The crystallites of the $\mathrm{TiO}_{2}$ thin films obtained for different coating cycles were characterized by X - Ray diffraction (XRD) using X'PERT PROX - ray diffractometer which was operated at $40 \mathrm{KV}$ and $30 \mathrm{~mA}$ with $\mathrm{CuK \alpha _{1 }}$ radiation of wavelength $1.5407 \AA$. The thickness of the films has been measured using Surfest SJ - 301 (Stylus profilometer). Optical properties of the films were examined by UV-Visible and Photoluminescence Spectrophotometer.UV - Visible spectra were recorded in the range of $200-800 \mathrm{~nm}$ by using the Schimadzu $1800 \mathrm{UV}$ - VIS - NIR spectrophotometer. The photoluminescence (PL) spectra were recorded using Schimadzu RF - 5301 with xenon lamp as the light source at room temperature at an excitation wavelength of $410 \mathrm{~nm}$. The surface morphology observation and elemental analysis were done by Quanta SEG - 200 FESEM and Bruker EDAX respectively.

\subsection{Structural analysis}

\section{Results and Discussion}

XRD patterns of the films annealed at $450^{\circ} \mathrm{C}$ for different number of coatings is shown in Fig. 2. The deposited $\mathrm{TiO}_{2}$ thin films show polycrystalline nature with high intensity peak in $\left(\begin{array}{lll}1 & 0 & 1\end{array}\right)$ orientation, anatase phase with tetragonal BCC structure. The other orientations (1 03 ), (2 $\left.\begin{array}{llll}0 & 0\end{array}\right),\left(\begin{array}{lll}1 & 0 & 5\end{array}\right)$ and $\left(\begin{array}{llll}2 & 1 & 3\end{array}\right)$ are also observed for all samples with low intensities, which is consistent with JCPDS file no.89-4921. From the XRD pattern, it is observed that the width of the peaks decrease and intensity of the peaks increase with increase in number of coating cycles. The film thickness values measured using Stylus profilometer are entered in Table 1.The crystallite size of the films were determined using the well-known Debye-Scherrer's formula:

$$
\mathrm{D}=\frac{0.9 \lambda}{\beta \cos \theta}(\mathrm{nm})
$$

Where $\mathrm{k}=0.94, \lambda=1.5407 \AA, \beta=$ Full Width Half Maximum (FWHM) and $\theta=$ Diffracting angle. We have found that the crystallite size increased from $6.25 \mathrm{~nm}$ to $35.46 \mathrm{~nm}$ as the number of coatings increases. The observed XRD datas are shown in Table 1. 

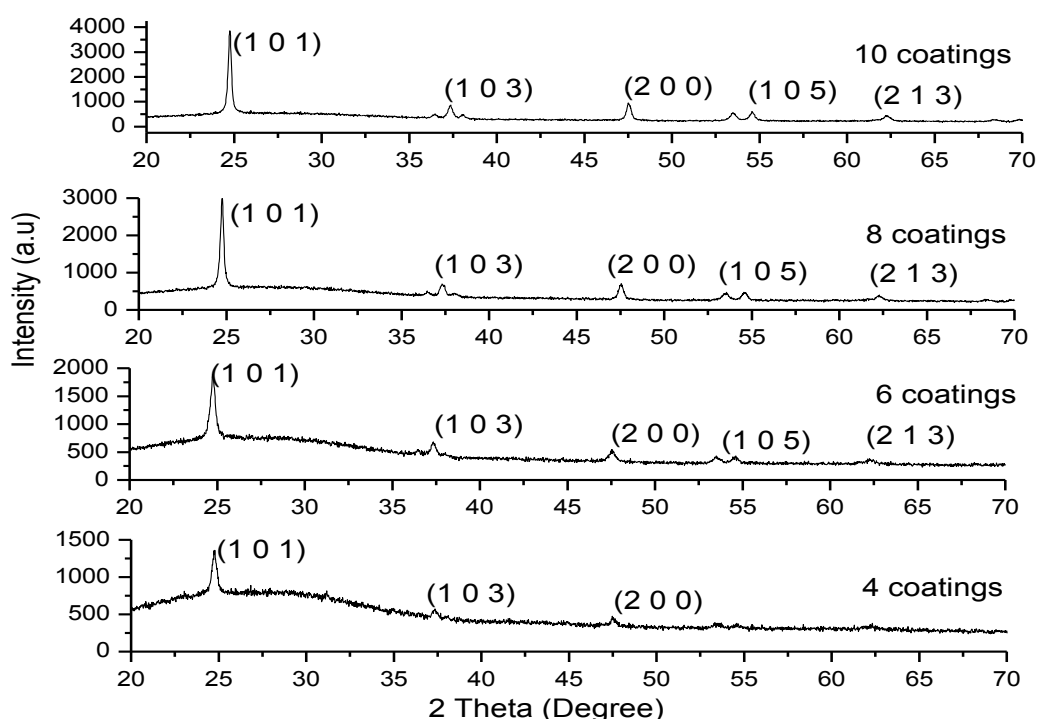

Fig. 2- XRD patterns of $\mathrm{TiO}_{2}$ thin films for different number of coatings

The origin of the strain in the films is related to the lattice misfit, which in turn depends upon the deposition conditions. The micro strain $(\mu)$ developed in the spin coated $\mathrm{TiO}_{2}$ thin films was calculated from the equation (2) [14],

$$
\mu=\frac{\beta \cos \theta}{4}
$$

\begin{tabular}{|c|c|c|c|c|c|c|}
\hline \multicolumn{7}{|c|}{ Table 1. Micro structural parameters of TiO thin film for different coating cycles } \\
\hline $\begin{array}{c}\text { Coating } \\
\text { cycles }\end{array}$ & $\begin{array}{c}\text { Thickness } \\
(\mu \mathrm{m})\end{array}$ & $\begin{array}{c}\text { FWHM } \\
\beta\end{array}$ & $\begin{array}{c}\text { Crystallite size } \\
\mathrm{D}(\mathrm{nm})\end{array}$ & $\begin{array}{c}\text { Dislocation } \\
\text { Density } \delta \\
10^{15}\left(\mathrm{lines} / \mathrm{m}^{2}\right)\end{array}$ & $\begin{array}{c}\text { Microstrain } \\
\mu \times 10^{-3}\end{array}$ & $\begin{array}{c}\text { No. of } \\
\text { crystallites } \\
\mathrm{Nx} 10^{16}\end{array}$ \\
\hline 4 & 0.36 & 1.36 & 6.25 & 25.19 & 0.3321 & 147.5 \\
\hline 6 & 0.87 & 0.64 & 13.28 & 5.65 & 0.1563 & 37.2 \\
\hline 8 & 0.92 & 0.29 & 29.30 & 1.17 & 0.0708 & 3.7 \\
\hline 10 & 1.07 & 0.24 & 35.46 & 0.79 & 0.0586 & 2.4 \\
\hline
\end{tabular}

where ' $\beta$ ' is full width at half maximum of the $\left(\begin{array}{lll}1 & 0 & 1\end{array}\right)$ peak and ' $\theta$ ' is the Bragg angle. The calculated values are given in table1.It is observed that the micro strain exhibits a decreasing tendency with increase in number of coating cycles. This type of micro strain changes may be due to the crystallization process in polycrystalline thin films. The number of crystallites ' $N$ ' was calculated from the relation (3)[15].

$$
N=\frac{\mathrm{t}}{D^{3}}
$$

where ' $t$ ' is the thickness of the film and ' $\mathrm{D}$ ' is the crystallite size. The growth mechanism involving dislocation is a matter of great importance. Dislocations are imperfection in a crystal associated with the mis-match of the lattice in one part of the crystal with respect to another part. Dislocation density values ' $\delta$ ' were determined using the relation (4) and given in Table 1.

$$
\delta=\frac{1}{D^{2}}
$$


(a)

(b)
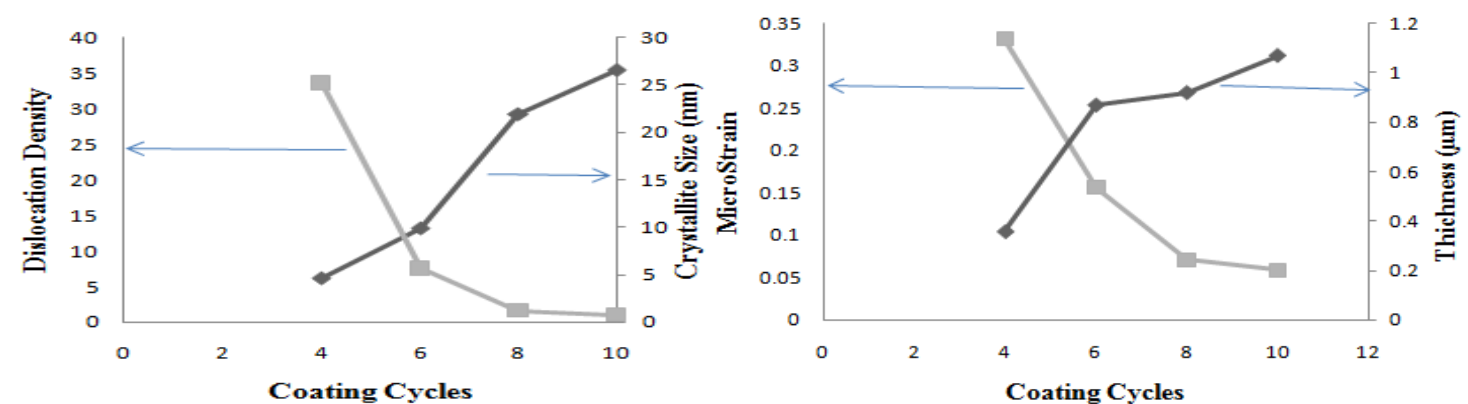

Fig. 3(a) - Variation of crystallite size and Dislocation density \& 3(b) - Thickness and Microstrain with number of coating cycles

It is observed that ' $\delta$ ' decreases with increasing number of coatings which imply decrease in lattice imperfection is due to increase in crystallite size. Fig. 3(a) \& (b) show the variation of crystallite size, Dislocation density, Thickness and Microstrain with number of coating cycles.

\subsection{Optical properties}

The transmission spectra for different number of coatings are shown in Fig.4. The deposited film is highly transparent in the visible range with an average transmittance reaching values upto $85 \%$ but the transmittance decreases when the number of coatings increases and it is due to increase in film thickness.Band gap energy $\left(\mathrm{E}_{\mathrm{g}}\right)$ can be estimated from the optical absorption measurements. The plot of $(\alpha \mathrm{h} v)^{2}$ with photon energy $(\mathrm{h} v)$ is shown in Fig. 5(a). The optical absorption data recorded in Table. 2 were analyzed using equations (5) of optical absorption in semiconductor near band edge.

$$
(\alpha h v)=\mathrm{A}\left(h v-E_{g}\right)^{\mathrm{n}}
$$

Where $\mathrm{E}_{\mathrm{g}}$ is the separation gap between bottom of conduction band and top of the valence band, hv is the photon energy and $\mathrm{n}$ is a constant,which depends on the probability of transition; it takes values as $1 / 2,3 / 2$, 2 , and 3 for direct allowed, direct forbidden, indirect allowed and indirect forbidden transitions respectively.

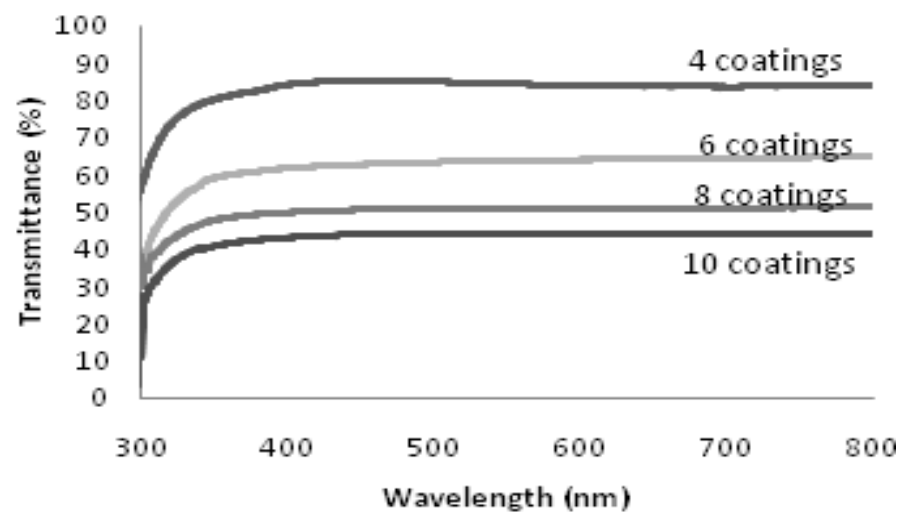

Fig. 4 -Transmittance spectra of $\mathrm{TiO}_{2}$ thin films for different number of coatings

If plot of $(\alpha h v)^{2}$ vs $(h v)$ is linear the transition is direct allowed (Fig.5 (a)) and $(\alpha h v){ }^{1 / 2} v s(h v)$ is linear the transition is indirect allowed (Fig.5 (b)). Extrapolation of the straight line portion to zero absorption coefficient $(\alpha=0)$, leads to estimation of bandgap energy $\left(\mathrm{E}_{\mathrm{g}}\right)$ value. The direct and indirect band gap energy values of the $\mathrm{TiO}_{2}$ thin films (Table. 2) are found to decrease with increase in number of coating cycles which might be the result of the change in film density, increase in crystal size and it may be attributed to the quantum confinement limit of nano particles. Similar observation regarding the direct band gap energy values were made in our previous work[16]. 
(b)
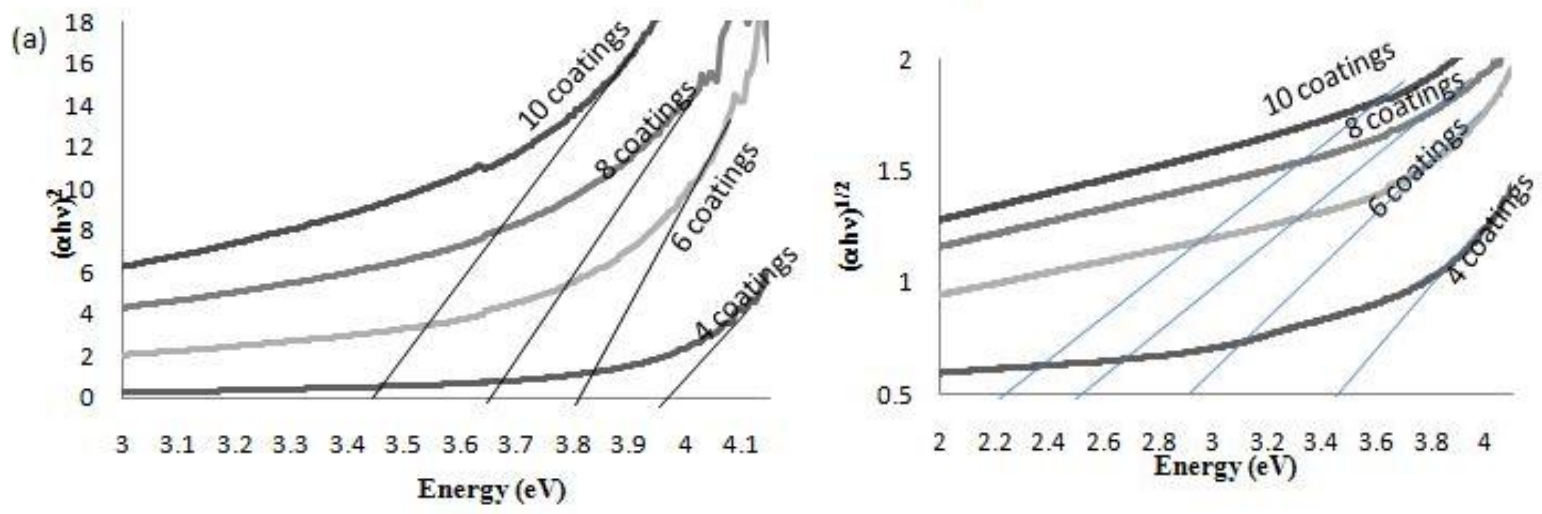

Fig.5. (a) Direct and (b) Indirect bandgap of $\mathrm{TiO}_{2}$ thin films for different number of coatings

\begin{tabular}{|c|c|c|c|c|}
\hline \multicolumn{5}{|c|}{ Table 2: Optical Data of $\mathbf{T i O}_{\mathbf{2}}$ ThinFilms } \\
\hline $\begin{array}{c}\text { Coating } \\
\text { cycles }\end{array}$ & Direct bandgap (eV) & $\begin{array}{c}\text { Indirect bandgap } \\
(\mathrm{eV})\end{array}$ & $\begin{array}{c}\text { Transmittance } \\
(\%)\end{array}$ & $\begin{array}{c}\text { PL Intensity (a.u) for peak at } \\
530 \mathrm{~nm}\end{array}$ \\
\hline 4 & 3.90 & 3.45 & 85 & 840 \\
\hline 6 & 3.80 & 2.90 & 63 & 439 \\
\hline 8 & 3.65 & 2.50 & 51 & 380 \\
\hline 10 & 3.45 & 2.20 & 44 & 51 \\
\hline
\end{tabular}

\subsection{Surface morphology and Quantitative Analysis}

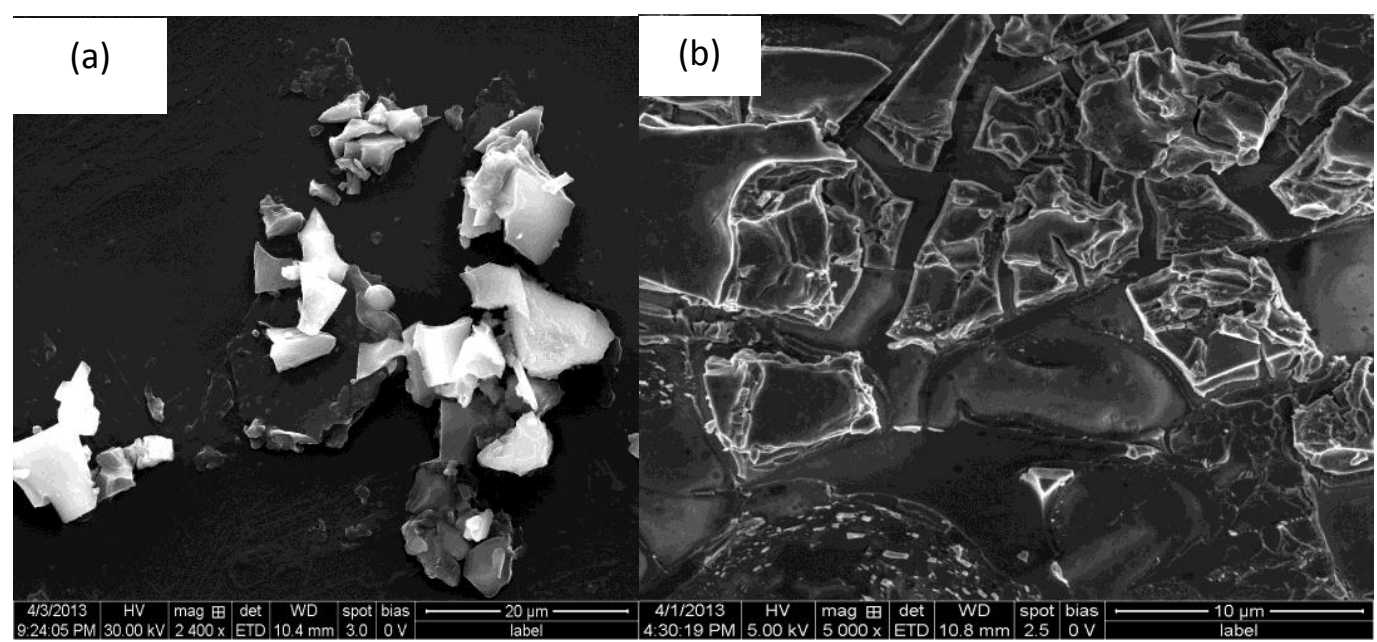


(c)

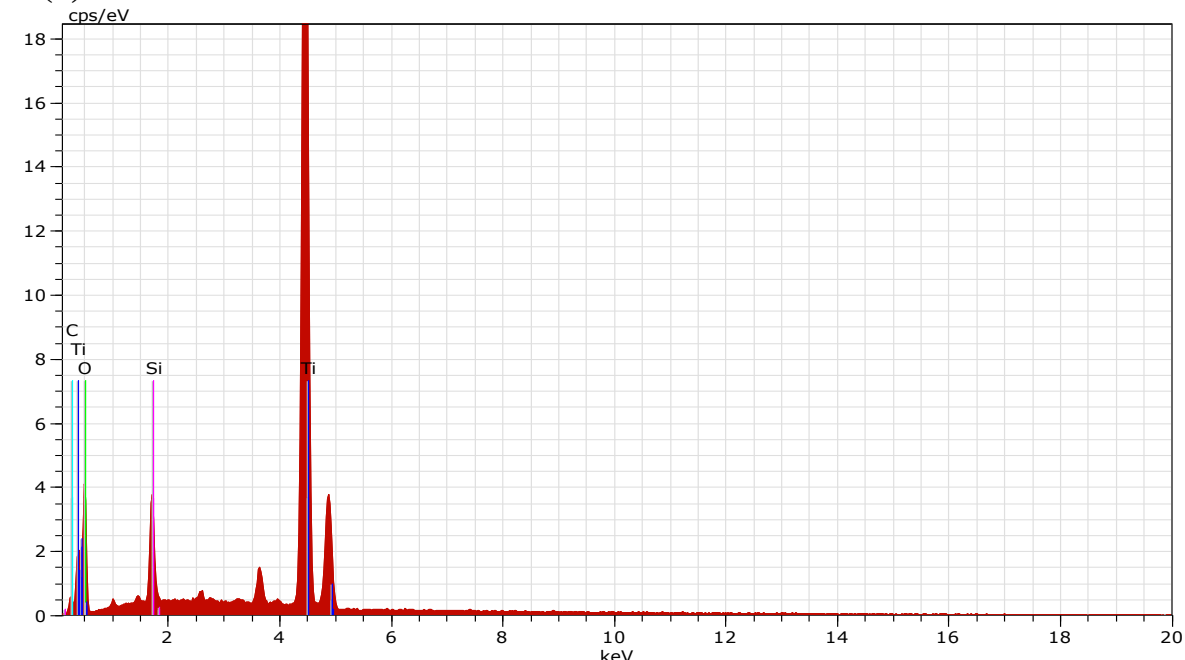

Fig. 6 - FESEM images of the film deposited for 4 coatings (a) and 8 coatings (b) of $\mathrm{TiO}_{2}$ thin films with EDAX spectrum (c).

FESEM micrographs of the nanocrystalline $\mathrm{TiO}_{2}$ thin films for $4 \& 8$ times coated films are shown in Fig .6 (a) \&6 (b). These images show loosely agglomerated, irregular smaller grains with flake like morphology. In the EDAX spectrum shown in Fig. 6(c), only characteristic peaks of Ti and $\mathrm{O}$ are observed with atomic ratio of Ti: $\mathrm{O}$ as $1: 4$ and weight ratio as 1:1.3.

\section{4 photoluminescence analysis}

The PL spectra of the spin coated $\mathrm{TiO}_{2}$ thin films for different number of coating cycles at room temperature for the excitation wavelength of $410 \mathrm{~nm}$ are shown in Fig. 7.The anatase $\mathrm{TiO}_{2}$ thin film PL emission peaks were observed at $530 \mathrm{~nm}(2.34 \mathrm{eV})$ and a shoulder at $485 \mathrm{~nm}(2.56 \mathrm{eV})$ for 6,8 , and 10states coating cycles. Flat PL band was found for 4 times coated film. The flat band can be attributed to the excitonic PL peaks trapped by thesurface states and defects [17]. In general, it has been observed that the transparency in the films adversely affects their PL response, i.e., the least transparent films exhibit the highest PL intensity [18]. Similar observations regarding PL intensity is made in our work also.

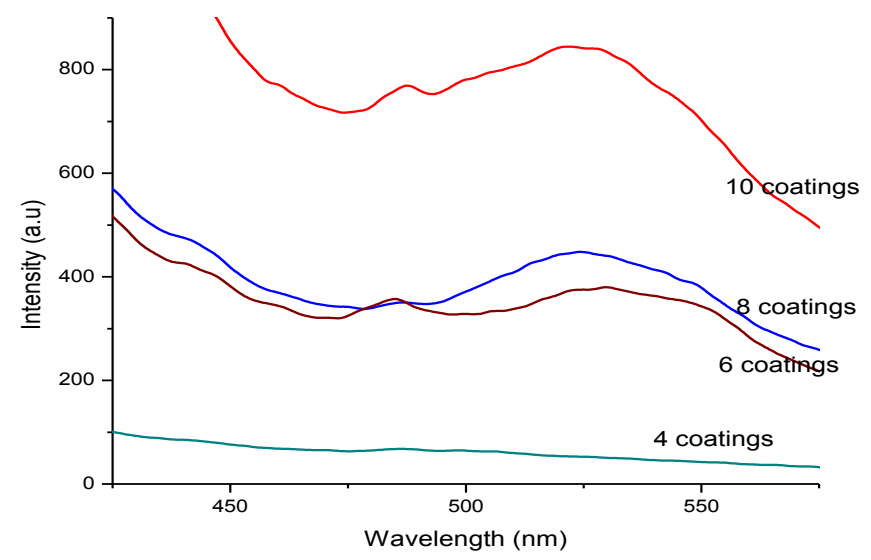

Fig. 7 PL spectra of the $\mathrm{TiO}_{2}$ thin films for different number of coatings

\section{Conclusion}


Sol-gel spin coating technique was used to deposit nanocrystalline $\mathrm{TiO}_{2}$ thin films with $\left(\begin{array}{lll}1 & 0 & 1\end{array}\right)$ predominant orientation for four different number of coatings on glass substrates annealed at $450^{\circ} \mathrm{C}$ for one hour. It was observed from XRD analysis that the crystallite size increases but dislocation density, micro grain and number of crystallites decreases with increasing number of coatings due to increase in film thickness. Optical study reveals that the transmittance and optical band gap (both direct and indirect) decrease but PL band emission intensity increase with increase in number of coating cycles. FESEM shows irregular particles with flake like morphology and the stoichiometic ratio was confirmed with EDAX spectra. The results confirm that thickness of film has strong effect on structural \& optical properties of nanocrystalline $\mathrm{TiO}_{2}$ thin films and high potential application in photo catalytic activities.

\section{Acknowledgement}

The authors are grateful to the University Grants Commission, New Delhi, India for extending financial support to carry out this work under Minor Research Project[F.No:MRP- 4315/12 (MRP/UGCSERO)].

\section{References}

[1] M.E .Yang Juan, Sen and J.M.F. Ferreira Hydrothd, Synthesis of nano sized Titania powders: Influence of tetra alkyl ammonium hydroxides on particle characteristics, J.Am.Ceram.Soc. 84(8), 2001, 1696-1706.

[2] Hang Ru-bin and Gao Lian, Effect of peptizationon phase transformation of $\mathrm{TiO}_{2}$ nanoparticles, J.Mater Res Bull., 36, 2001,1957- 1965.

[3] M. Anpo, T.O. Shima, S. Kodama and Y. Kubokawa, Photo catalytic hydrogenation of Propyne with water on small particle titania: size quantization effects and reaction intermediats, J.phys.chem, 91, 1987, 4305-4310.

[4] S.Ruan, F. Wu, T. Zhang, W.Gao, B.Xu and M. Zhao, Surface state of $\mathrm{TiO}_{2}$ nanoparticlesAnd photo catalytic degradation of methyl orange in aqueous $\mathrm{TiO}_{2}$ dispersions, Mater.chem.phys, 69, 2001, 7-9.

[5] S. Liu and X. Chen, A visible light response $\mathrm{TiO}_{2}$ photocatalyst realized by cationic S-doping and its Application for phenol degradation, J.Hazard.mater,152(1), 2008,48-55.

[6] H. Honda, A. Ishizaki, R. Soma, K. Hashimoto and A. Fujishima, Application of photocatalytic Reactions caused by $\mathrm{TiO}_{2}$ film to improve the maintenance factor of lighting systems,J.Illum.Eng.Soc.Winter, 42-49. 1998.

[7] K. Kobayakawa, C. Sato, Y. Sato, and A. Fujishima, Continuous flow photo reactor packed withTitanium dioxide immobilized on large silica gel beads to decompose oxalic acid in excess Water, J.Photochem.Photobiol.A:Chem. 118, 1998, 65-69.

[8] A.Rothschild, F. Edleman, Y. Komem and F. Csandey, Sensing behavior of $\mathrm{TiO}_{2}$ thin films Exposed to air at low temperatures, Sensor.Actuat B-Chem. 67, 2000, 282-289.

[9] Y. Liu, W. Zhu, O. Tan and Y. Shen, Structural and gas sensing properties of ultrafine $\mathrm{Fe}_{2} \mathrm{O}_{3}$ prepared by plasma enhanced chemical vapor deposition, Mater.Sci.Eng.B. 47, 1997, 171- 176.

[10] C. Chen, W. Zhu, T. Yu, X. Chen and X. Yao, Preparation of metal organic decomposition Derived strontium zirconate dielectric thin films, Appl.surf.Sci. 2111, 2003, 244-249.

[11] X.Liu, S. Tao and Y. Shen, Preperation and characterization of nanocrystaline $\alpha \mathrm{Fe}_{2} \mathrm{O}_{3}$ by a sol - gel process, Sens.actuat.B-Chem. 40, 1997, 161-65.

[12] A.Taurino, M. Epifani, T. Toccoli, S. Iannotta and P. Siciliano, Innovative aspects in thin film Technologies for nanostructures materials in gas sensor devices, Thin Solid Films. 436, 2003,52 - 63.

[13] A. Phani and S. Santucci, Structural Characterization of Nickel Titanium Oxide synthesized by Sol - gel spin coating technique, Thin Solid Films. 396, 2001, 1 - 4.

[14] Ovid' Ko,Interfaces and misfit defects in Nanostructured and polycrystalline films, Rev.Adv.Mater.Sci.,1,2000, 61.

[15] R. Ferro, J.A. Rodriguez and A. Vigil.Morales - Acevedo, Chemical composition and electrical conduction mechanism for CdO: $\mathrm{F}$ thin films deposited by spray Pyrolysis, Mater.Sci.Eng.B. 87, 2001, 83-86.

[16] P. Malliga, J. Pandiarajan, N. Prithivikumaran and K. Neyvasagam, Effect of film thickness on structural and optical propertiesofTiO $\mathrm{T}_{2}$ thin films, IEEE Xplore, , Proc. IEEE Conf. on Advanced NanoMaterials \& Emerging Engineering Technologies,Chennai,India, 2013, 547-550.

[17 L.Q.Jing, Y.C. Qu and P.Q. Wang,, Sol.Energy.Mater.Sol.C. 90, 2006, 295.

[18] Amita Verma and Amish G Joshi, structural, Optical, Photoluminescence and Photocatalytic Characteristics of sol - gel derived $\mathrm{CeO}_{2}-\mathrm{TiO}_{2}$ films, Indian Journal of Chemistry, 48A, 2009, 161-167. 